\title{
PENGARUH VARIASI TEMPERATUR HARDENING DAN TEMPERING PADUAN AlMgSi-Fe12\% HASIL PENGECORAN TERHADAP KEKERASAN
}

\author{
${ }^{(1)}$ Sumpena, ${ }^{(2)}$ Wardoyo \\ ${ }^{(1,2)}$ Prodi Teknik Mesin Universitas Proklamasi 45 Yogyakarta \\ ${ }^{(1)}$ Email: sumpenast@yahoo.co.id \\ Jl. Proklamasi No.1 Babarsari Yogyakarta
}

\begin{abstract}
The purpose of this research is to know the effect of Heat Treatment HardeningTempering Alloy AlMgSi-Fe12\% foundry result to hardness and toughness. The test was carried out on raw material and material test specimen after obtaining Hardening heat treatment at $600^{\circ} \mathrm{C}$ and quenching with SAE 20 oil medium. While Tempering variation at temperature $200^{\circ} \mathrm{C}$, temperature $250^{\circ} \mathrm{C}$ and temperature $300^{\circ} \mathrm{C}$ with detention time for $15 \mathrm{~min}$ at each temperature, each heat treatment. Hardness testing method is done by standard micro Vickers test method with $100 \mathrm{gf}$ loading. The result of raw material testing for hardness value is $60,92 \mathrm{VHN}$. Test results after heat treatment process at temperature $200^{\circ} \mathrm{C}$ cause hardness value increased by $63,50 \mathrm{VHN}$. At temperature $250^{\circ} \mathrm{C}$ cause hardness value decreased to 59,94 VHN. At temperature $300^{\circ} \mathrm{C}$ cause hardness value increase to $76,98 \mathrm{VHN}$
\end{abstract}

keywords: hardness, heat treatment, alloy AlMgSi-Fe12\%

\section{PENDAHULUAN}

Aluminium merupakan logam ringan memiliki ketahanan korosi yang baik dan penghantar listrik yang baik. Sebagai tambahan terhadap kekuatan mekaniknya sangat meningkat dengan penambahan $\mathrm{Cu}, \mathrm{Mg}, \mathrm{Si}, \mathrm{Sn}, \mathrm{Zn}$, secara satu persatu atau bersamaan memberikan sifat-sifat fisik lainnya seperti ketahanan korosi, ketahanan aus, koefisien pemuaian rendah. Matrial ini dipergunakan di dalam penggunaan yang luas bukan saja untuk peralatan rumah tangga tapi juga dipakai untuk keperluan matrial pesawat terbang, mobil, kapal laut, konstruksi. (Surdia T. Saito S. 2000).

Aluminium paduan secara umum dapat di klasifikasikan menjadi dua yaitu heat treatable dan non heat treatable. Paduan heat treable dapat diperkuat dengan memberikan perlakuan hardening, pengerasan dengan fariasi suhu dan proses perlakuan panas lainnya. Pada paduan non heat treatable dapat diperkuat dengan pengerjaan dingin, dan annealing untuk memperlunak akibat dari proses pengerasan. Paduan ini terdiri dari Al-Mn, Al-Mg, dan Al-Si. Sedangkan paduan yang terkandung pada heat treable adalah $\mathrm{Cu}, \mathrm{Zn}$, dan $\mathrm{Mg}$ serta Si.

Paduan AlMgSi mempunyai sifat mekanik mampu bentuk yang baik, tahan korosi dan sebagai tambahan dapat diperkuat dengan perlakuan panas setelah pengerjaan. Paduan jenis ini banyak dipergunakan untuk rangka-rangka konstruksi. Karena paduan dalam sistim ini mempunyai kekerasan yang cukup baik tanpa mengurangi hantaran listrik, maka dipergunakan untuk kabel penghantar listrik. (Surdia T. Shiroku S. 1999)

Perlakuan panas adalah proses perlakuan panas sampai temperatur tertentu kemudian didinginkan dengan cara tertentu untuk memberikan sifat yang lebih baik. Untuk pemanasan tersebut dipergunakan dapur yang umumnya dengan listrik, dan dengan gas, karena pengukuran temperatur harus dapat seteliti mungkin. (Soedjono. Mashudi. 1978).

Hardening adalah memanaskan logam sampai temperatur tertentu selama 
masih dalam keadaan tidak merubah bentuk logam dan ditahan dalam waktu beberapa lama pada temperatur itu, kemudian didinginkan dengan cepat (quenching), sehingga menimbulkan suatu susunan yang keras. Perlakuan panas dengan cara ini bertujuan membuat logam menjadi keras. Proses hardening ini menyebabkan pada susunan atomatom yang teratur sehingga menimbulkan tegangan dan logam itu menjadi keras.

Tempering adalah memanaskan kembali logam yang telah dikeraskan melalui proses hardening yang bertujuan untuk mengurangi tegangan dalam dan didinginkan secara berlahan untuk menghasilkan keuletan dan sifat mekanik yang tangguh. (Soedjono. Mashudi. 1978).

Tujuan Penelitian adalah untuk mengetahui pengaruh perlakuan panas Hardening dan Tempering terhadap sifat kekerasan dan sifat ketangguhan (Impact) hasil pengecoran paduan $\mathrm{AlMgSi}-12 \%$.

\section{LANDASAN TEORI}

Paduan aluminium diklasifikasikan dalam berbagai standar oleh berbagai Negara di dunia. Saat ini klasifikasi yang sangat terkenal dan sempurna adalah standar aluminium Association di Amerika (AA) yang didasarkan atas standar terdahulu dari Aloca (Aluminium Company of America). Paduan tempaan dinyatakan dengan satu atau dua angka, sedangkan paduan coran dinyatakan dengan 3 angka. Standar AA menggunakan penandaan dengan 4 angka. Angka pertama menyatakan sistem paduan dengan unsur yang ditambahkan, yaitu: Al murni, $\mathrm{Al}-\mathrm{Cu}$, Al-Mn, Al-Si, Al-Mg, Al-Mg-Si dan Al-Zn. (Surdia T. Saito S. 2000).

\section{A. Paduan AlMgSi}

Pada aluminium sedikit ditambahkan $\mathrm{Mg}$ pengerasan penuaan sangat jarang terjadi, tetapi apabila secara simultan mengandung $\mathrm{Si}$, maka dapat dikeraskan dengan penuaan penuaan panas setelah perlakuan pelarutan. Hal ini disebabkan karena senyawa $\mathrm{Mg}_{2} \mathrm{Si}$ berkelakuan sebagai komponen murni dan membuat keseimbangan dari aluminium. Sebagai paduan praktis dapat diperoleh paduan 5053, 6063dan 6061 . Paduan ini mempunyai kekuatan kurang sebagai bahan tempaan dibandingkan dengan paduan-paduan lainnya, tetapi sangat liat mampu bentuk yang baik ntuk penempaan.

Paduan AlMgSi mempunyai mampu bentuk yang baik pada ekstrusi dan tahan korosi, dan sebagai tambahan dapat diperkuat dengan perlakuan panas setelah pengerjaan. Paduan 6063 dipergunakan banyak untuk rangkarangka konstruksi. Karena paduan dalam sistim ini mempunyai kekuatan yang cukup baik tanpa mengurangi hantaran listrik, maka dipergunakan untuk kabel tenaga. Dalam hal ini pencampuran dengan $\mathrm{Cu}, \mathrm{Fe}$ dan $\mathrm{Mn}$ perlu dihindari karena unsur-unsur itu menyebabkan tahanan listrik menjadi tinggi. (Surdia T. Saito S. 2000).

\section{B. Perlakuan Panas}

Perlakuan panas adalah suatu proses pemanasan sampai suhu tertentu dan selama waktu tertentu kemudian diikuti dengan pendinginan dengan media pendinginan tertentu untuk mengubah sifat fisik dan mekanik logam tanpa mengubah ukurannya. Dalam proses Perlakuan panas ada 3 (tiga) hal yang harus dilewati yaitu:

\section{Proses pemanasan}

Perlakuan panas berlaku untuk logam dalam keadaan padat karena memiliki struktur kristal. Benda amorpha tidak dapat dikeraskan karena susunan atomnya tidak teratur sedangkan benda kristal dapat dikeraskan karena memiliki struktur atom yang teratur. Benda amorpha mencair dan membeku secara berangsur sedangkan benda kristal titik cair dan beku dengan cara tertentu. Titik ubah atau titik henti, yaitu: Titik ubah 
atas dan titik ubah bawah. Keduanya merupakan batas perubahan kristal logam pada saat dipanaskan dan didinginkan. Jika pemanasan sudah mencapai titik ubah bawah maka perlit sudah mulai berubah menjadi austenit sedangkan sementit tidak harus berubah menjadi austenit karena sementit sendiri sudah bersifat keras. Jika pemanasan logam belum mencapai titik ubah bawah maka belum terjadi perubahan struktur atom.

\section{Waktu penahanan (Holding Time)}

Waktu penahanan tergantung pada: udara di dalam dapur, kapasitas panas, jenis logam, sumber panas yang digunakan, kemampuan dapur memancarkan panas, komposisi udara, jenis dapur, ukuran benda kerja.

\section{Proses pendinginan (quenching)}

Media pendingin sangat berpengaruh terhadap hasil pada proses perlakuan panas. Media pendingin yang umum digunakan:

a) Air memberikan pendinginan cepat sekali dan untuk mempertinggi daya pendinginan dilarutkan garam dapur $5 \%-10 \%$.

b) Minyak memberikan pendinginan sedang dan untuk persyaratan tertentu dipakainya minyak pendingin yang khusus.

c) Udara memberikan pendinginan lambat, sehingga sirkulasinya dibuat ringan.

d) Garam memberikan pendinginan teratur, sangat bagus pada proses penyepuhan.

\section{Perlakuan panas Hardening}

Hardening adalah memanaskan logam sampai temperatur tertentu dengan waktu beberapa lama pada temperatur itu, kemudian didinginkan dengan cepat, sehingga menimbulkan suatu susunan yang keras. Hardening bertujuan untuk meningkatkan kekerasan, ketahanan aus dan ketangguhan dengan kombinasi kekerasan. Proses hardening ini menyebabkan pada susunan atom-atom yang teratur timbul tegangan dan logam itu menjadi keras. Adapun tahapantahapan proses hardening adalah sebagai berikut:

Pertama proses pemanasan sehingga struktur ferit berubah menjadi struktur austenite seluruhnya. Kedua proses penahanan pada temperatur tertentu (holding). Ketiga setelah dipanaskan hingga membentuk austenit kemudian didinginkan secara cepat (mendadak). Pendinginan cepat akan menghasilkan struktur martensit karena garis pendinginan lebih cepat yang nantinya akan tetap terbentuk fase austenit. Akan tetapi hasilnya akan bersifat rapuh karena tegangan dalamnya besar.

Gambar 1 menunjukan diagram fasa paduan $\mathrm{AlMg}_{2} \mathrm{Si}$ yang berasal dari larutan yang menurun dari $\mathrm{Mg}_{2} \mathrm{Si}$ terhadap larutan padat $\mathrm{Al}$ dari temperatur tinggi ketemperatur yang lebih rendah.

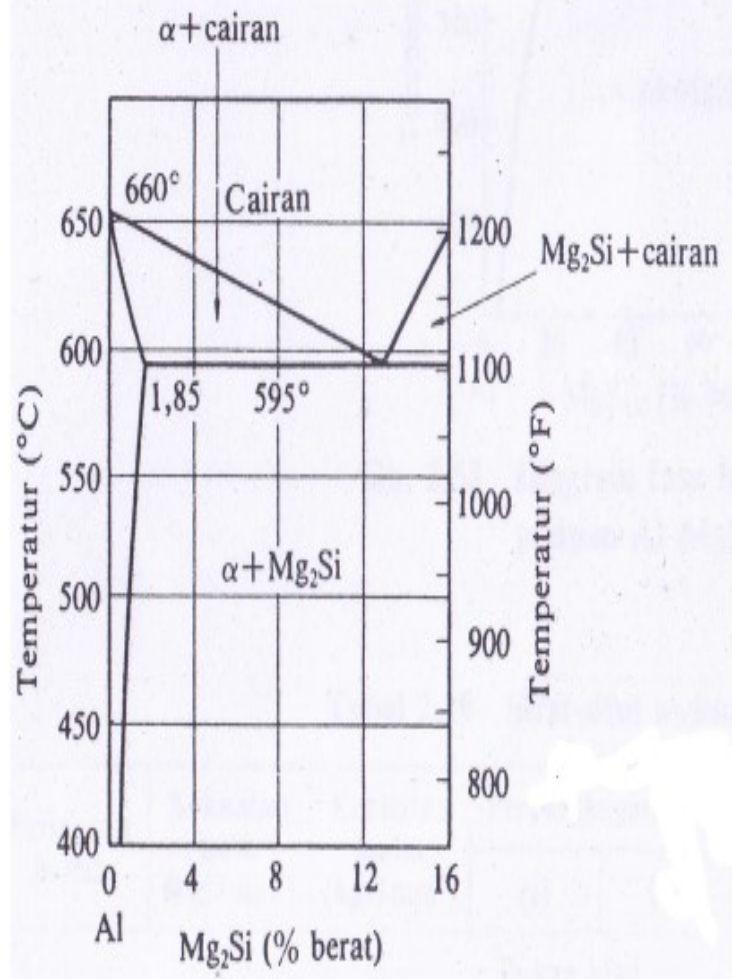

Gambar 1. Diagram fasa paduan $\mathrm{AlMg}_{2} \mathrm{Si}$

(Sumber: Surdia T. Saito S. 2000 hal.139).

Berdasarkan gambar 1 menjadi acuan proses perlakuan hardening dan tempering. Aluminium dengan 
kandungan $\mathrm{MgSi}$ sebesar 6,82\% maka proses hardening dilakukan pada temperatur $600^{\circ} \mathrm{C}$. Pada diagram diatas perlakuan dibawah temperatur $600^{\circ} \mathrm{C}$ material tidak mengalami perubahan bentuk sedangkan perlakuan diatas temperatur $600^{\circ} \mathrm{C}$ material mengalami perubahan bentuk dan mencair.

\section{Perlakuan Panas Tempering}

Tempering adalah suatu proses panas yang bertujuan untuk menurunkan kekerasan benda kerja, mengurangi tegangan dalam yang menyebabkan benda kerja bersifat rapuh, merubah struktur kristal atom sehingga bersifat lunak dan mudah dikerjakan. Sehingga dari proses tersebut didapatkan benda kerja yang memiliki sifat kombinasi antara kerasan, keliatan, keuletan (tahan terhadap impact), kekuatan dan berstruktur kristal stabil.

Pada proses hardening benda kerja yang dihasilkan bersifat keras akan tetapi rapuh, sehingga tidak cocok untuk beberapa penggunaan. Sifat rapuh disebabkan terbentuknya martensit yang berlebihan yang mengakibatkan struktur kristal atom menjadi stabil. Ketika dipanaskan kembali atom karbon yang terjebak di dalam struktur kristal atom akan berdifusi (pemerataan kadar tanpa dinding pemisah) membentuk grafit dan kembali menjadi ferit dan sementit yang stabil.

Tahapan proses tempering adalah sebagai berikut: karena proses tempering ini adalah proses lanjutan dari hardening. Maka pertama benda kerja dikeraskan terlebih dahulu setelah diquencing kemudian benda dipanaskan kembali pada temperatur antara $150^{\circ} \mathrm{C}-400^{\circ} \mathrm{C}$ untuk mendapatkan sifat yang lebih lunak lebih ulet. Harus diperhatikan proses tempering adalah waktu dan temperatur yang digunakan. Pada tahap terakhir proses tempering adalah pendinginan dalam udara terbuka.

Pada proses tempering temperatur yang digunakan adalah temperatur dibawah proses hardening, jika proses tempering dilakukan diatas temperatur perlakuan hardening maka sifat setelah perlakuan hardening akan hilang.

\section{E. Pengujian Kekerasan.}

Pengujian kekerasan dengan cara penekanan banyak digunakan di industri permesinan. Pengujian kekerasan yang menggunakan metode penekanan ada tiga jenis, yaitu pengujian kekerasan metode Rockwell, Brinell dan metode Vickers. Metode Brinell dan Vickers memiliki prinsip dasar yang sama dalam menentukan angka kekerasannya menitik beratkan pada penghitungan kekuatan bahan uji terhadap pembebanan setiap daya luas penampang bidang yang menerima pembebanan tersebut. Sedangkan metode Rockwell menitik beratkan pada pengukuran kedalaman hasil penekanan alat penekan yang membentuk bekasnya pada benda uji. (Koswara E. Sudjana H. 1999).

\section{Pengujian kekerasan Vickers}

Proses pengujian kekerasan metode Vickers diatur dengan standar DIN 50133. Yang termasuk di dalamnya antara lain tentang pemakaian indentor. Piramida intan dengan sudut $136^{\circ}$ puncak piramida berbentuk garis lurus. Ada dua rentang kekuatan yang berbeda, yaitu micro $(10 \mathrm{~g}-1000 \mathrm{~g})$ dan macro $(1 \mathrm{~kg}-$ $100 \mathrm{~kg})$.

Didasarkan pada cara memperoleh angka kekerasan yang diberikan oleh Vickers, rumus tersebut merupakan angka kekuatan bahan uji terhadap pembebanan pada setiap luas penampang bidang yang menerima pembebanan itu berbentuk piramida, bagian permukaan berbentuk segi empat, dan berdiagonal ( $\mathrm{mm})$.

Pada mesin uji tertentu yang sepesifik, biasanya mikroskop pengukur sudah terpasang secara langsung dan bisa digunakan setelah penekanan dilakukan tanpa merubah kedudukan bahan uji dari posisi anvil. Tentu saja, proses pengukuran dengan mikroskop yang 
langsung terpasang akan menjaga ketelitiannya, bila dibandingan dengan mikroskop terpisah. Meskipun demikian proses pengujian, baik yang menggunakan mikroskop langsung atau pun terpisah, bahan uji hendaknya dilakukan paling sedikit 3 kali agar diperoleh harga ukur yang akurat.

Hasil pengukuran kekerasan Vickers, dalam bentuk angka kekerasan bahan logam, dinyatakan dalam harga satuan tertentu, menurut ketentuan dan standar yang baku demikian pula angka kekerasannya. Satuan kekerasan Vickers ini sudah diakui oleh standar internasional dan digunakan oleh semua industri di seluruh dunia serta dapat dikonversikan dengan satuan dari harga kekerasan lain dalam berbagai metode. (Koswara E. Sudjana H. 1999).

Untuk mengetahui angka kekerasan Vickers suatu bahan uji dapat menggunakan rumus berikut.

$$
\mathrm{Hv}=1,8544 \frac{\mathrm{P}}{\mathrm{d}^{2}}\left(\mathrm{~kg} / \mathrm{mm}^{2}\right)
$$

Keterangan:

$\mathrm{Hv}=$ Hardness Vickers (angka kekerasan Vickers) satuan $\left(\mathrm{Kg} / \mathrm{mm}^{2}\right)$

$\mathrm{P}=$ Gaya $(\mathrm{Kg})$

$\mathrm{d}^{2}=$ Diagonal indentasi $(\mathrm{mm})$

\section{Tinjauan Pustaka}

Beberapa hasil penelitian yang telah dilkukan peneliti sebelumnya antara lain:

\begin{tabular}{|c|c|c|c|c|c|c|c|}
\hline No & \multicolumn{2}{|l|}{$\begin{array}{l}\text { Nama } \\
\text { Peneliti }\end{array}$} & $\begin{array}{l}\text { Judul } \\
\text { Penelitian }\end{array}$ & \multicolumn{2}{|c|}{$\begin{array}{l}\text { Variasi } \\
\text { material }\end{array}$} & $\begin{array}{l}\text { Kekerasan } \\
\text { brinell } \mathrm{HB} \\
\left(\mathrm{kg} / \mathrm{mm}^{2}\right)\end{array}$ & $\begin{array}{l}\text { Nilai impact } \\
\mathrm{J} / \mathrm{mm}^{2}\end{array}$ \\
\hline \multirow[t]{5}{*}{\begin{tabular}{|l|}
1 \\
\end{tabular}} & \multirow{5}{*}{\multicolumn{2}{|c|}{$\begin{array}{l}\text { Sigit } \\
\text { Gunawan dan } \\
\text { Sigit Budi } \\
\text { Hartono } 2016\end{array}$}} & \multirow{5}{*}{$\begin{array}{l}\text { Efek } \\
\text { perlakuan } \\
\text { panas aging } \\
\text { terhadap } \\
\text { kekerasan } \\
\text { dan } \\
\text { Ketangguhan } \\
\text { impak paduan } \\
\text { aluminium aa } \\
514.0\end{array}$} & \multicolumn{2}{|c|}{$250^{\circ} \mathrm{C}$} & $31,16 \mathrm{~kg} / \mathrm{mm}^{2}$ & 1,446 \\
\hline & & & & \multicolumn{2}{|c|}{$300^{\circ} \mathrm{C}$} & $29,66 \mathrm{~kg} / \mathrm{mm}^{2}$ & 1,412 \\
\hline & & & & \multicolumn{2}{|c|}{$350^{\circ} \mathrm{C}$} & $32,66 \mathrm{~kg} / \mathrm{mm}^{2}$ & 1,244 \\
\hline & & & & \multicolumn{2}{|c|}{$400^{\circ} \mathrm{C}$} & $30,83 \mathrm{~kg} / \mathrm{mm}^{2}$ & 1.211 \\
\hline & & & & \multicolumn{2}{|c|}{$450^{\circ} \mathrm{C}$} & $32,5 \mathrm{~kg} / \mathrm{r}$ & 1,446 \\
\hline No & \begin{tabular}{|l} 
Nama \\
Peneliti
\end{tabular} & $\begin{array}{l}\mathrm{Ju} \\
\mathrm{Pe}\end{array}$ & in & Temper & $\mathrm{Si}$ & $\begin{array}{l}\text { Kekerasan } \\
\text { VikersHV } \\
\left(\mathrm{N} / \mathrm{mm}^{2}\right)\end{array}$ & $\begin{array}{l}\text { Impackj/m } \\
\mathrm{m}^{2}\end{array}$ \\
\hline \multirow[t]{11}{*}{2} & \multirow{11}{*}{\begin{tabular}{|l|} 
Toga \\
Agung \\
Saputro, \\
2014.
\end{tabular}} & \multirow{11}{*}{\multicolumn{2}{|c|}{$\begin{array}{l}\text { Analisa Heat } \\
\text { Treatment } \\
\text { Pada } \\
\text { Aluminium } \\
\text { Magnesium } \\
\text { Silikon } \\
\text { (AlMgSi) } \\
\text { Dengan } \\
\text { Silikon (Si) } \\
(1 \%, 3 \%, 5 \%) \\
\text { Terhadap Sifat } \\
\text { Fisis Dan } \\
\text { Mekanis. }\end{array}$}} & & Si $1 \%$ & $42,23 \mathrm{~N} / \mathrm{mm}^{2}$ & $0,014 \mathrm{j} / \mathrm{mm}^{2}$ \\
\hline & & & & & Si $3 \%$ & $41,42 \mathrm{~N} / \mathrm{mm}^{2}$ & $0,013 \mathrm{j} / \mathrm{mm}^{2}$ \\
\hline & & & & & Si 5\% & $\mathrm{N} / \mathrm{mm}^{2}$ & $0,012 \mathrm{j} / \mathrm{mm}^{2}$ \\
\hline & & & & \multirow[t]{3}{*}{$125^{\circ} \mathrm{C}$} & Si $1 \%$ & $43,88 \mathrm{~N} / \mathrm{mm}^{2}$ & $0,021 \mathrm{j} / \mathrm{mm}^{2}$ \\
\hline & & & & & Si $3 \%$ & $41,98 \mathrm{~N} / \mathrm{mm}^{2}$ & $0,019 \mathrm{j} / \mathrm{mm}^{2}$ \\
\hline & & & & & Si 5\% & $41,18 \mathrm{~N} / \mathrm{mm}^{2}$ & $0,018 \mathrm{j} / \mathrm{mm}^{2}$ \\
\hline & & & & \multirow[t]{3}{*}{$125^{\circ} \mathrm{C}$} & Si $1 \%$ & $44,89 \mathrm{~N} / \mathrm{mm}^{2}$ & $0,033 \mathrm{j} / \mathrm{mm}^{2}$ \\
\hline & & & & & Si $3 \%$ & $43,54 \mathrm{~N} / \mathrm{mm}^{2}$ & $0,016 \mathrm{j} / \mathrm{mm}^{2}$ \\
\hline & & & & & Si 5\% & $42,29 \mathrm{~N} / \mathrm{mm}^{2}$ & $0,025 \mathrm{j} / \mathrm{mm}^{2}$ \\
\hline & & & & & $\mathrm{Si}$ & $45,97 \mathrm{~N} / \mathrm{mm}^{2}$ & $0,045 \mathrm{j} / \mathrm{mm}^{2}$ \\
\hline & & & & & \begin{tabular}{|l} 
S13\% \\
Si 5\%
\end{tabular} & $\frac{44,21 \mathrm{~N} / \mathrm{mm}^{2}}{43,22 \mathrm{~N} / \mathrm{mm}^{2}}$ & \begin{tabular}{|l|}
$0,037 \mathrm{j} / \mathrm{mm}^{2}$ \\
$0,032 \mathrm{j} / \mathrm{mm}^{2}$
\end{tabular} \\
\hline
\end{tabular}

\begin{tabular}{|c|c|c|c|c|c|}
\hline 3 & $\begin{array}{l}\text { Nama } \\
\text { Peneliti }\end{array}$ & $\begin{array}{l}\text { Judul } \\
\text { Penelitian }\end{array}$ & $\begin{array}{l}\text { Variasi } \\
\text { material }\end{array}$ & $\begin{array}{l}\text { Kekerasan } \\
\text { brinell } \mathrm{HB} \\
\left(\mathrm{kg} / \mathrm{mm}^{2}\right)\end{array}$ & $\begin{array}{l}\text { Nilai } \\
\text { impact } \mathrm{J} / \\
\mathrm{mm}^{2}\end{array}$ \\
\hline & \multirow{4}{*}{$\begin{array}{l}\text { Wisnanings } \\
\text { ih dan M. } \\
\text { Yunus, } \\
2017\end{array}$} & \multirow{4}{*}{$\begin{array}{l}\text { Pengaruh } \\
\text { temperatur } \\
\text { aging terhadap } \\
\text { paduan } \\
\text { alumunium } \\
\text { Seri } 6069 \\
\text { terhadap nilai } \\
\text { kekerasan dan } \\
\text { kekuatan } \\
\text { impact }\end{array}$} & Raw material & $28 \mathrm{~kg} / \mathrm{mm}^{2}$ & 66,00 \\
\hline & & & $165^{\circ} \mathrm{C}$ & $47,6 \mathrm{~kg} / \mathrm{mm}^{2}$ & 95,33 \\
\hline & & & $175^{\circ} \mathrm{C}$ & $56,2 \mathrm{~kg} / \mathrm{mm}^{2}$ & 97 \\
\hline & & & $185^{\circ} \mathrm{C}$ & $58 \mathrm{~kg} / \mathrm{mm}^{2}$ & 78,67 \\
\hline
\end{tabular}

\section{METODE PENELITIAN}

\section{A. Bahan Penelitian}

Bahan paduan $\mathrm{Al} 78,13 \%, \mathrm{Mg} 2,99 \%$, Si $3,83 \%-\mathrm{Fe} 12 \%$.

\section{B. Alat Penelitian}

1) Dapur pemanas (furnace)

2) Alat uji kekerasan mikro Vickers

3) Alat uji ketangguhan impact metode charpy

\section{Diagram Alir Penelitian}

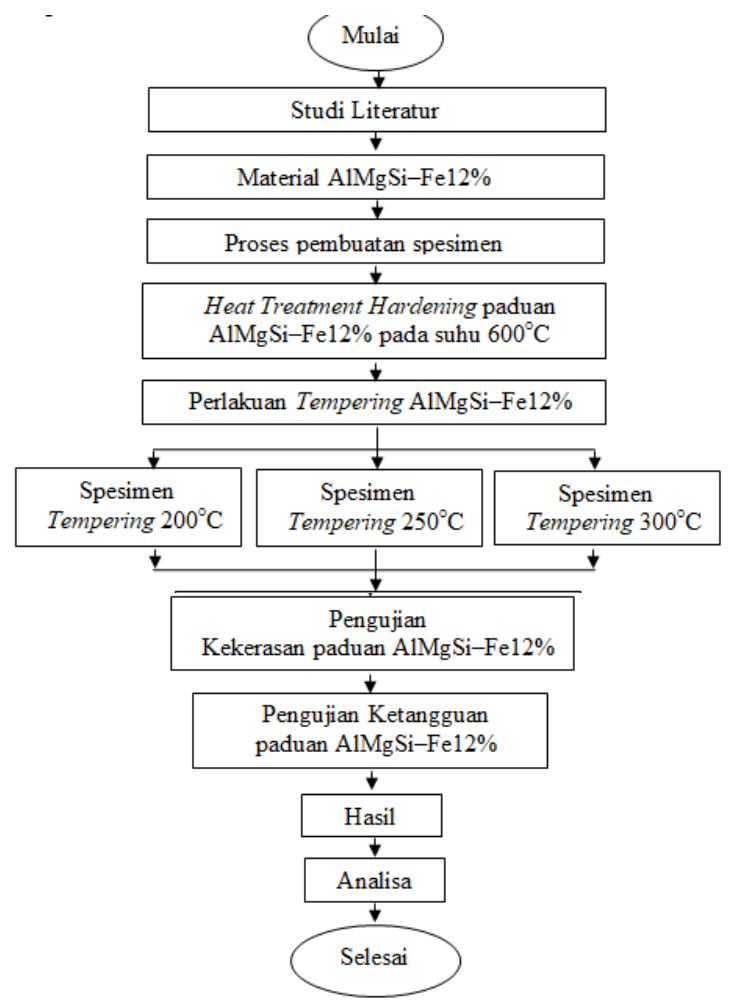

Gambar 2. Diagram Alir Penelitian

IV. HASIL DAN PEMBAHASAN

\section{A. Hasil dan pembahasan pengujian kekerasan.}


Hasil pengujian kekerasan mikro vickers raw material dan material dengan proses perlakuan panas dan diquencing ke dalam oli SAE 20 dilanjutkan perlakuan pemanasan ulang dengan variasi temperatur, maka didapatkan data sebagai berikut:

\section{Nilai kekerasan VHN}

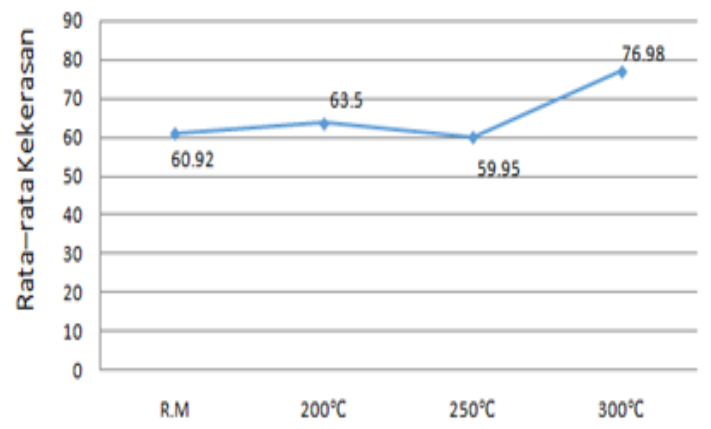

Gambar 3. Grafik Hasil Pengujian Kekerasan.

Data dari gambar 2 menunjukan nilai kekerasan untuk raw material sebesar 60,96 VHN. Nilai kekerasan akibat perlakuan panas pada temperatur $200^{\circ} \mathrm{C}$ sebesar 63,50 VHN berarti mengalami peningkatan sebesar 2,54 VHN dari raw material. Nilai kekerasan akibat perlakuan panas pada temperatur $250^{\circ} \mathrm{C}$ sebesar 59,94 VHN berarti mengalami penurunan sebesar 1,02 VHN dari raw material. Terdapat udara didalam tungku sehingga saat proses pemanasan terjadi oksidasi yang mengakibatkan menurunnya nilai kekerasan. Nilai kekerasan akibat perlakuan panas pada temperatur $300^{\circ} \mathrm{C}$ sebesar 76,98 VHN berarti mengalami peningkatan sebesar $16,02 \mathrm{VHN}$ dari raw material.

Pada proses hardening sepesimen mengalami kejutan sehingga proses difusi tidak berlangsung hanya terjadi perubahan struktur jaringan kristal. Karena proses pendinginan berlangsung sangat cepat maka menimbulkan tegangan pada sepesimen dan benda uji bersifat keras dan rapuh.

Terdapatnya oksigen di dalam tungku sehingga menyebabkan dekarburasi yang menyebabkan menurunnya nilai kekerasan. Menurunnya nilai kekerasan juga disebabkan oleh kegagalan perlakuan panas hal ini dapat terjadi karena kurangnya proses kontrol yang tidak mencukupi.

Faktor lainnya disebabkan saat pendinginan adalah waktu transfer saat quenching pemindahan terlalu lama akan menyebabkan temperatur turun secara cepat maka akan menghilangkan efek pengerasan.

\section{KESIMPULAN \\ Pada proses perlakuan panas} hardening dengan temperatur $600^{\circ} \mathrm{C}$ diquenching kedalam oli SAE 20 dan dilanjutkan proses tempering dengan variasi temperatur $200^{\circ} \mathrm{C}$, temperatur $250^{\circ} \mathrm{C}$ dan temperatur $300^{\circ} \mathrm{C}$ masingmasing temperatur dipertahankan selama 15 menit didapatkan kesimpulan sebagai berikut:

a) Setelah dilakukan pengujian mikro vickers menghasilkan nilai kekerasan tertinggi pada temperatur $300^{\circ} \mathrm{C}$ sebesar 76,98 VHN dan nilai kekerasan terendah pada temperatur $250^{\circ} \mathrm{C}$ sebesar $59,95 \mathrm{VHN}$.

\section{DAFTAR PUSTAKA}

Bagus S. Dan Media N. (2011) Perubahan Nilai Kekerasan Dan Struktur Mikro (Al-Mg-Si) Akibat Variasi Temperatur Pemanasan. Perpustakaan UPN Veteran Jakarta.

Hendra S. (2014) Pengaruh Perlakuan Panas Dan Penuaan Terhadap Sifat Mekanis Pada Aterial Komposit Matrik Al-4,5\%Cu-4\%Mg/10\%Sic. FakultasTeknik Universitas Gunadarma Depok Jakarta.

Purnomo (2017) Material Teknik Malang Jawa Timur: Seribu Bintang

Sigit G. Dan Sigit B. Efek Perlakuan Panas Aging Terhadap Kekerasan 
Dan Ketangguhan Impact Paduan Aluminium Aa 514.0 Jurusan Teknik Mesin Sttnas Yogyakarta.

Surdia, T., Dan Saito S. (2000). Pengetahuan Bahan Teknik. Jakarta: Pradnya Paramita.

Sriwardani , N., Heat Treatment Process Proses Perlakuan Panas Surakarta Lpp Uns Dan Uns Press 2009.

Soedjono Dan Mashudi. (1978) Pengetahuan Bahan 1. Departemen Pendidikan Dan Kebudayaan.

Surdia, T., \& Chijiwa, K. (1982). Teknik Pengecoran Logam. Jakarta: Pradnya Paramita.

Toga A. S. (2014) Analisa Heat Treatment Pada Aluminium Magnesium Silikon (Al-Mg-Si) Dengan Silikon (Si) (1\%, 3\%, 5\%) Terhadap Sifat Fisis Dan Mekanis. Naskah Publikasi Universitas Muhamadiyah Surakarta.

Wismaningsih Dan M. Yunus (2017) Pengaruh Temperature Aging Terhadap Paduan Aluminium Seri 6069 Terhadap Nilai Kekerasan Dan Kekuatan Impact. Fakultas Teknik Universitas Siang Bumi Rawa Jurai Lampung Indonesia.

Wahyu, P. (2008) Pengaruh Perlakuan Panas Terhadap Struktur Mikro Dan Kekerasan Coran Paduan AlMg-Si. Mekanika, Jurnal Fakultas Teknik Universitas Negri Surakarta. 